\title{
LIBROPUEBLO/HERRILIBURU: EL PROYECTO EDITORIAL DE RAMIRO PINILLA Y JOSÉ JAVIER RAPHA BILBAO (1977-1986)
}

\author{
Javier Feijoo Morote \\ Université de Pau et des Pays de l'Adour (UPPA) \\ Universidad del País Vasco / Euskal Herriko Unibertsitatea (UPv/EHu)
}

\section{Resumen}

Libropueblo/Herriliburu fue una editorial vizcaína fundada por Ramiro Pinilla y José Javier Rapha Bilbao que se desarrolló en los años de la transición española (1977-1986) y que supuso un intento revolucionario por remover los cimientos de la industria editorial. Ambos autores quisieron abanderar la fórmula «del escritor directamente al lector» y propiciar la incardinación de la figura del escritor en la dinámica de los movimientos políticos y sociales de España. El proyecto conllevó la ejecución de todos los pasos de la cadena de producción editorial, así como una política de libros a precio de costo que eliminaba el porcentaje de beneficio para el autor. La realidad cultural y artística de la transición española corre paralela a la génesis, evolución y decadencia final de la editorial, que permite explicar, asimismo, las particularidades de la carrera literaria de Ramiro Pinilla y su posterior evolución como narrador.

Palabras clave: Transición, mercado editorial, narrativa, Ramiro Pinilla, movimientos sociales.

\section{LIBROPUEBLO/HERRILIBURU: THE PUBLISHING PROJECT OF RAMIRO PINILLA AND JOSÉ JAVIER RAPHA BILBAO (1977-1986)}

\begin{abstract}
Libropueblo/Herriliburu was a publishing house from Biscay (Basque Country, Spain) founded by Ramiro Pinilla and José Javier Rapha Bilbao which was developed during the years of the Spanish transition to democracy (1977-1986). It was a revolutionary attempt to undermine the structure of the publishing industry in Spain. The motto «directly from writer to reader» took a leading role in the editorial plan and both authors promoted the incorporation of the writers into Spanish political and social contemporary movements. The project involved every step of the publishing process, as well as a price policy that eliminated the author's profit contribution. The cultural and artistic reality
\end{abstract}


of the Spanish transition runs parallel to the genesis, evolution and final decline of the publishing house. This also explains the peculiarities of Ramiro Pinilla's literary career and his subsequent evolution as a novelist.

Keywords: Spanish transition, publishing market, narrative, Ramiro Pinilla, social movements.

En 1977, tras la muerte de Franco, José Javier Rapha Bilbao y Ramiro Pinilla pusieron en marcha una iniciativa literaria que afrontó el negocio de la industria editorial desde una perspectiva original y reivindicativa. Libropueblo/Herriliburu basó sus presupuestos en una oposición práctica a la comercialización de la cultura, tratando de acortar las distancias entre el escritor y el lector y ofreciendo los libros a precio de coste. José Javier Rapha Bilbao (Getxo, 1943) había obtenido, durante los años setenta, un éxito considerable como autor de textos dramáticos. Su actividad teatral estuvo íntimamente ligada a la figura de Luis Iturri y a su grupo Akelarre. Sus obras más importantes fueron La corte de Pedro Botero (1972) y su versión de Don Volpone (1974). Viajero, anticuario, docente, empresario y periodista (trabajó en Londres entre 1969 y 1974 para la revista Pueblo, la Agencia EFE y como freelance), su relación con la publicación literaria quedó suspendida a partir de la desaparición de Libropueblo hasta su reaparición en 2001, con las obras La Guerra de los Milagros y iSsssssssh! (Bermingham Editorial) ${ }^{1}$. Por su parte, Ramiro Pinilla (Bilbao, 1923-Getxo, 2014) se inscribió en el campo literario nacional con el éxito inesperado de su primera novela Las ciegas hormigas (1960). Posteriormente, publicó en 1969 En el tiempo de los tallos verdes y en 1971, obtuvo el galardón de Finalista del Premio Planeta por su novela Seno. Desde entonces, su apuesta, entre otras cosas, por la edición independiente, la acción política, los talleres de escritura creativa y los movimientos asociativos ciudadanos le apartaron de los grandes circuitos editoriales durante más de treinta años. Su reaparición se produjo en 2004 de la mano de la editorial Tusquets, con la obra en la que había trabajado durante veinte años: Verdes valles, colinas rojas, un colosal testimonio de la transformación de la sociedad industrial que le valió el reconocimiento unánime del público lector, crítico y académico y la obtención de numerosos premios.

\section{Desencuentros editoriales}

La idea de crear una editorial como Libropueblo nació de la íntima amistad de ambos autores, como una fuerza surgida de sus reivindicaciones polí-

1 Posteriormente, ha publicado, a través de la autoedición, La descubrí con su pie izquierdo por detrás de su cuello bebiendo una taza de té (2010) y Exhumación (2011). En la actualidad, sigue publicando un cuento mensual a través de su blog en internet: <http://raphabilbao.blogspot.com.es $>$. 
ticas y de sus frustraciones literarias, provocadas por la sensación de agravio recibido por las editoriales hasta ese momento. El origen de las desavenencias de Pinilla con Destino, la editorial que publicó su novela Las ciegas hormigas, ganadora del premio Nadal (1960) y del Premio de la Crítica (1962), fue la venta unilateral de los derechos de su novela a una productora alemana, como señala el propio Pinilla (González, 2012: 4):

A mí me gusta hablar claro, y les pregunté qué me iban a dar. Y me dijeron que 15.000 pesetas. Hoy es poco y entonces también lo era, y dije que no merecía la pena dar la novela por ese dinero. Eso no les gustó. Un día se plantó aquí todo un equipo de la televisión alemana y me dijeron que venían a filmar la novela. Yo no sabía nada, los editores lo habían firmado todo para evitar mi negativa. A partir de ahí la cosa fue de mal en peor.

Evidentemente, las condiciones que firmó con Destino le dejaron en una posición jurídica de indefensión frente a la voluntad de la editorial y Pinilla comenzó a identificar la industria comercial de la literatura con un canal de desatención y desprecio al escritor ${ }^{2}$. Tras el rechazo de la novela El salto y el fracaso de ventas y de crítica de su siguiente novela En el tiempo de los tallos verdes (1969), Pinilla finalizó su relación con Destino y, tras obtener una beca de la Fundación March, escribió Seno, la novela con la que recibió el galardón de Finalista del Premio Planeta en 1971. Pese al premio, tanto la gala como las reacciones del dueño de la editorial y de algunos miembros del jurado le reafirmaron en su visión negativa de los intereses comerciales de las grandes editoriales. Lo contaba con estas palabras Fernando Aramburu (2006: 1):

Días antes del fallo, una llamada telefónica anuncia al escritor la obtención del susodicho premio. Felicidades. Se le invita a acudir sin falta a Barcelona, al sarao anual que todavía se celebra. Pinilla se desplaza en compañía de una hija. Llega el momento de las fingidas deliberaciones y el primer premio, zas, se lo dan a otro cuyo renombre garantiza mayores ventas. Durante seis meses, la editorial Planeta demorará la publicación de Seno, uno de los grandes títulos de Pinilla. De este modo se reduce el riesgo de que los críticos comparen un libro de alto valor literario con la plasta ganadora. Aquella noche, Lara (que en paz descanse) se acerca al novelista chasqueado y le tiende un billete consolador de cinco mil pesetas de las de entonces. ¿Generosidad? ¿Petición indirecta de disculpas? ¡Naranjas de la China! Las cinco mil cucas

2 De hecho, las malas relaciones con Destino se alargaron hasta más allá de 2006, ya que, arguyendo que quedaban en sus depósitos más de cien ejemplares de Las ciegas hormigas, no permitían que otra editorial (Tusquets, en este caso) la publicara. Finalmente, las negociaciones concluyeron con éxito y la obra pudo reeditarse en 2010, gracias a las gestiones del editor Antonio Lamadrid (véase Landaburu, 2010 y el prólogo a la edición de Tusquets del propio Pinilla, en el que cuenta todo ello con detalle). 
le serán más tarde descontadas al escritor de la retribución correspondiente a su premio como finalista.

Años después, en 1977, inmersa toda la sociedad española en unas circunstancias políticas extraordinarias, se produjo el acicate definitivo para tomar la decisión de crear Libropueblo. Su novela Antonio B., el rojo, ciudadano de tercera; España, España fue publicada por la editorial Albia de Bilbao a un precio de mercado, desde su punto de vista, excesivamente alto: 700 pesetas (Díaz de Guereñu, 2015). Inmerso ya en un explícito compromiso social, Pinilla no pudo admitir que, tras lograr su publicación, un libro que tenía como principal motor la denuncia social a partir de la narración de las miserias de un ser humano debiera tener un coste que impedía su consumo para gran parte de la población: «No admito que un libro mío valga setecientas pesetas» (Igartua y Díez Ortiz, 1978: 34).

El caso de Rapha Bilbao fue similar en cuanto a las malas relaciones con las editoriales. Su enfado estuvo motivado por las dificultades que encontraba para publicar, así como las condiciones económicas que las editoriales le habían exigido: en aquellos años ya había publicado un par de libros y no había logrado recibir la más mínima retribución, a pesar de la buena acogida de su novela Doña Anita de Gon-Ber (1977) (Rapha Bilbao, 2016).

\section{Política y CUltura EN LA transición}

Como señala Pablo Sánchez León, la importancia participativa de los movimientos sociales en la transición ha quedado habitualmente subordinada al protagonismo de los partidos políticos. Sin embargo, en los últimos años, ha aumentado considerablemente el interés sobre las acciones llevadas a cabo por la sociedad civil, subrayando su importante participación en el proceso de transición a la democracia ${ }^{3}$. Tras la muerte de Franco, gran parte de la sociedad española vivió unos momentos de euforia y celebración, conscientes de que la presencia física del dictador era el último sostén de un régimen ya muy debilitado y de que su desaparición suponía, por tanto, el inicio del desmantelamiento de la represión del sistema franquista y el advenimiento de la tan ansiada legalización de los partidos políticos y la democracia. Pese a que «muy pocos españoles corrieron a engrosar las

3 Sánchez León (2010: 95): «The consensus has been challenged in recent years, though. Emerging views underline the relevance of a brief but rather intensive cycle of protest between 1975 and 1979 that seems to have influenced short-term political events and even shape some of the longer-term characters of political culture in contemporary Spain (Tarrow, 1995); parallel to this trend is the growth of a literature focused on civil society that underlines the independent role of common people on the move in bringing democracy (Pérez Díaz, 1993; Radcliff, 2007)». 
filas de los partidos y sindicatos que presuntamente deberían dirigir esa ruptura» ${ }^{4}$, la participación ciudadana tuvo un protagonismo indiscutible en los años setenta:

The social mobilization around urban issues that occurred in the neighbourhoods of most Spanish cities throughout the 1970s was, to our knowledge, the largest and most significant urban movement since $1945^{5}$.

Insertos en este contexto, Rapha Bilbao y Pinilla participaron activamente en la asunción de la llegada de un tiempo nuevo. Como actores conscientes de ese proceso de transformación social, dieron un paso más allá de la teorización y pusieron en práctica un concepto distinto de publicación y, por tanto, de escritura, lectura y edición. Esos fueron los años en que la intervención política de Ramiro Pinilla fue más activa y directa: participó de los actos en torno a la llamada Platajunta ${ }^{6}$ y, meses después, se afiliaría al Partido Comunista que, en aquellos momentos, promovía la alianza de los trabajadores con las fuerzas de la cultura. Como recuerda Mainer (Mainer y Juliá, 2000: 87), se produjo en aquellos años un cambio decisivo en la consideración de la función del intelectual en la vida social:

El prestigio que los intelectuales alcanzaron como encarnaciones fidedignas de la conciencia colectiva en los años sesenta se mantuvo muy vivo todavía en los primeros momentos de la transición. Así lo demostraron las listas de adherentes que el Partido Comunista y el Partit Socialista Unificat de Catalunya esgrimieron en las primeras elecciones generales.

Pinilla llegó, incluso, a presentarse en varias ocasiones en las listas electorales tanto del PCE (número 10 en las listas por Vizcaya al Congreso de

4 Mainer y Juliá (2000: 46). Señala Juliá: «Hasta mayo de 1977 habían solicitado su inscripción en el registro 111 partidos, de los que 78 quedaron legalizados, pero otros muchos actuaban sin cumplir el trámite reglamentario. La ola siguió creciendo hasta marzo de 1979, cuando pudieron contabilizarse más de $300 \ldots$ al mismo tiempo, la gente no mostró ningún entusiasmo por engrosar las filas de los partidos, el número de afiliados no pasaba de 200 en la mayoría de los casos».

5 Sánchez León (2010: 96) recuerda que se registraron doce millones de jornadas laborales de huelga en 1976, dieciocho millones en 1977 y diez millones y medio en 1978, comparado con una media de dos millones anuales en los cinco años anteriores (Pérez Díaz, 1980: 34). A pesar de la baja afiliación sindical, la participación en huelgas fue indudablemente masiva.

${ }^{6}$ Véase Wilhelmi Casanova (2014: 159-169). Coordinación Democrática (conocida popularmente como Platajunta) fue una asociación política fundada en 1976 que trató de aglutinar todos los movimientos de oposición franquista. La coalición fue, fundamentalmente, el producto de la fusión entre la Junta Democrática de España (liderada por el Partido Comunista de España) y la Plataforma de Convergencia Democrática (liderada por el Psoe de Felipe González). 
los Diputados en 1977) como de Euskadiko Ezkerra ${ }^{7}$ (número 18 en 1984). Explicaba el autor (Erroteta y Elordi, 1980: 48):

Entonces, en medio de aquella insolidaridad, resolví mi vida y, cuando lo logré — de forma humilde, por supuesto, ya que mis apetencias materiales son muy reducidas-, me di cuenta de que eso no bastaba. Yo, que creía ser un ser solitario, tomé conciencia de que no lo era del todo. Este pequeño descubrimiento me empujó a incorporarme al mundo. Participé en movimientos como la Asamblea Democrática de Vizcaya y decidí ingresar en el Partido Comunista.

Libropueblo/Herriliburu tomó parte activa de aquellos años transicionales, llenos de contradicciones, impulsos y espacios de participación social que la acción ciudadana contribuyó a completar en manifestaciones culturales y sociales como la de la editorial vizcaína. En este sentido, la trayectoria editorial de Libropueblo ejemplifica uno de los caminos recorridos por la sociedad española en aquellos años. No hay que olvidar, por ello, la relación implícita que mantuvo el proyecto con la fuerza social del Partido Comunista (más oficialmente en Pinilla ${ }^{8}$ y de modo más tácito y simpatizante en Rapha Bilbao): sus acciones, lemas, colaboraciones y presupuestos ideológicos eran una traslación (personalizada, sin duda) del impulso de ruptura con el franquismo, de renovación social y de integración política en democracia que representaba el eurocomunismo asumido por Carrillo como secretario general ${ }^{9}$. Las energías de movilización social de la transición posibilitaban e, incluso, potenciaban, la ejecución de acciones que la nueva libertad de acción exigía (Pinilla, en Anónimo, 1982):

Libropueblo es como un intento ecológico dentro de los modos con que funciona la literatura entre nosotros... No me gusta la comercialización de la literatura, la comercialización del arte. Tengo derecho, no solo a que no me guste, sino a demostrar que no me gusta. Tengo derecho, no solo a manifestar de palabra que no me gusta, sino a elegir un cierto comportamiento que explique hasta qué grado no me gusta.

7 En 1982 se produjo la convergencia entre el PC de Euskadi (PCE-EPK) y Euskadiko Ezkerra (EE) merced al desmarque de la lucha armada que protagonizó el sector de ETA-pm proclive a la organización EIA, el núcleo básico de EE con Mario Onaindia a la cabeza.

8 Ceberio (1977) y Pérez Carrera (2014).

9 Carrillo (2006: 548) contextualiza la asunción ideológica del eurocomunismo alrededor de 1975 y en relación a las conversaciones con el Partido Comunista Italiano. Entre otras razones, esa decisión fue motivada por el contexto político de la transición, pues «solo con una línea impecablemente democrática podíamos romper los comunistas españoles la resistencia social contra nuestro partido». En el IX Congreso del PCE celebrado en abril de 1978, Carrillo anuncia el abandono del leninismo. En mayo de 1979, el partido socialista renuncia al marxismo, anticipándose, de este modo, en más de una década «a las posteriores renuncias marxistas de la izquierda europea» (Vilarós, 1998: 10). 


\section{VISIÓN Y MISIÓN}

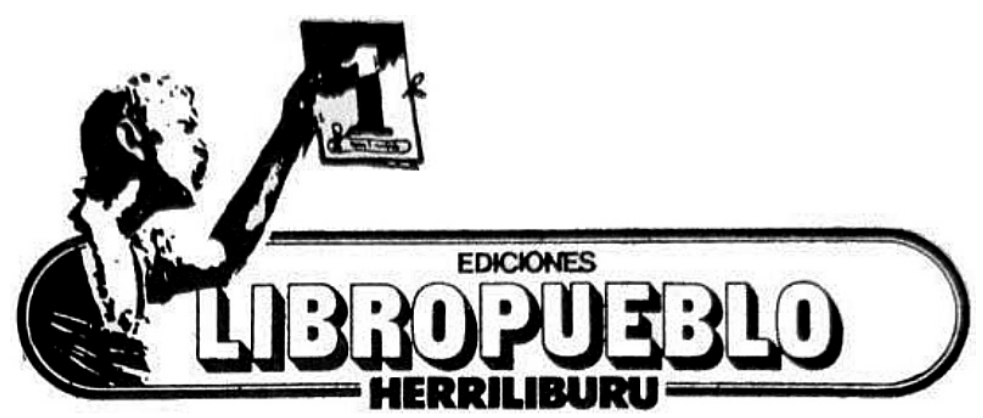

De acuerdo con José Carlos Mainer (1990: 21), entre los años 1973 y 1975 , el artista español tenía que enfrentarse a tres tareas inacabadas:

La necesidad de aprender a vivir con el pasado propio de español que vivía en un periodo todavía denominado sintomáticamente como de posguerra; la urgencia de tomar partido frente a la confusa atmósfera de miedo, decepción y egocentrismo que rodeó la segunda mitad de los setenta; y la obligación de continuar escribiendo, pintando o filmando dentro de un marco cultural que parecía haber agotado todas las fuentes de originalidad y que parecía estar condenado a la hipocresía comercial de la sociedad de consumo.

En 1978, tras sus nefastas experiencias con las empresas editoriales, Pinilla ya había sufrido las decepciones y frustraciones que motivaron su nuevo posicionamiento como escritor. La función social de la literatura pasó a ser su objetivo principal y a ella dedicó sus esfuerzos (literarios, políticos y editoriales) durante los primeros años de la transición. Su mala conciencia por el precio de su última novela y el callejón sin salida de la economía de mercado fueron determinantes en la configuración de su propia editorial (Pinilla, en Anónimo, 1979):

Libropueblo es un intento de tratar al libro y a la cultura desde un enfoque distinto. Son dos nuestras metas: alcanzar un mayor estrechamiento entre el artista y el pueblo, en bien de la popularización de la cultura; y ofrecer a este pueblo libros no a precio de negocio, sino a precio de costo. Entendemos, pues, que la cultura no debe ser comerciable.

La idea principal que abordaban (y que se convirtió en el lema de la pancarta que les acompañó en su venta al público) era evitar el engranaje comercial del libro y poder hacer realidad la fórmula «del escritor directamente al lector». Y no solo en un sentido económico sino también a través 
del deseo de abandonar la figura aislada del escritor y lograr su implicación reivindicativa dentro del entramado social. Evidentemente, en sus intenciones prevalecía un posicionamiento de denuncia directa del negocio del libro en un sistema de mercado capitalista. Baste esta cita para remarcarlo (Pinilla, en Anónimo, 1978):

A falta de un Estado socialista que edite los libros en grandes tiradas que abaraten sus costos y lleguen directamente al lector, nosotros hemos optado por ese intento de socializar lo que produzcamos.

Esa multiplicación del precio del libro era visto como un ataque a la propia idea de cultura popular que ambos escritores defendían. No dudaban, sin embargo, de que su gesto era una acción simbólica y de que una editorial como la suya no era la solución final al problema del libro sino un modo de llamar la atención para intentar provocar la intervención de la sociedad (y del Estado) en la búsqueda de alternativas (Pinilla y Rapha, en Anónimo, 1979):

No es más que un intento de denuncia. Sin dinero, sin medios, sin organización, tratamos de demostrar que los libros no tienen por qué ser tan caros [...] Quisiéramos dejar bien claro que no estamos denunciando a editores, distribuidores o libreros, sino denunciando un sistema social de mercado que permite una mercantilización tan abusiva de un producto cultural.

Libropueblo/Herriliburu fue a la busca del lector y de la concienciación social de todo el campo literario. La vinculación entre literatura y ánimo de lucro era considerada como una lógica maliciosa y, por ello, la supresión del beneficio se constituyó como premisa del nuevo proyecto. Estos fueron los cuatro principios del manifiesto que acompañaban a cada ejemplar:

LIBROPUEBLO es una pequeña organización de trabajadores de la cultura para editar sus propios libros a precios realmente populares, sin obtener beneficio, sólo recuperando lo invertido.

LIBROPUEBLO es una denuncia de los precios de los libros, una denuncia de un sistema social de mercado.

LIBROPUEBLO es consciente de no ser la solución al problema del libro. Esta solución habrá de traerla la propia sociedad, no un grupo de ciudadanos voluntariosos. Pero alguien tenía que demostrar ya que no tiene razón de ser tan caro el libro.

LIBROPUEBLO, al no estar concebido como empresa comercial, no tiene reparo en mostrar sus cuentas: 


\section{Proceso editorial}

Rapha y Pinilla cumplieron personalmente las tres funciones principales del acto de edición que establece Robert Escarpit (1971: 60): «elegir, fabricar y distribuir»y sus tres servicios correspondientes: «comité literario, oficina de fabricación y departamento comercial». Esta estructura implicó unas limitaciones innegables de riesgo y difusión, por lo que los escritores que optaron por participar tuvieron que comprometerse personalmente con la venta hasta que su obra se agotara. La estructura de la editorial conllevaba la supervisión (cuando no la ejecución) de todos los pasos de la cadena de producción, incluso en la imprenta, lo que implicaba un control absoluto sobre todos los detalles editoriales (sellos, cintas, precios, carpetas, cuerdas, tipografía y el infinito etcétera).

Los cuatro primeros ejemplares se vendieron dentro de una carpeta de cartón gris anudada con una cuerda de esparto. Según recuerda el propio Rapha Bilbao (2016), esta encuadernación también corrió a cargo de ambos escritores (y sus familias), que debían doblar cada cartón, hacerle personalmente los dos agujeros e introducir el cordel por cada uno de ellos. Una vez encarpetado cada ejemplar impreso, organizaron su propia red de distribución, no solo por librerías, sino también por bares y centros de trabajo. La venta al público se realizaba de un modo insólitamente directo y ambulante a través de una mesilla de camping tras la que se colocaba una pancarta ${ }^{10}$ con el nombre de la editorial ${ }^{11}$.

Durante la transición, a través de Libropueblo, Pinilla y Rapha lograron que se crearan incluso colas para comprar libros ${ }^{12}$. El lugar de venta de referencia fue la Plaza Nueva de Bilbao, a la que acudían todos los domingos por la mañana. Su actividad principal se realizó en Vizcaya, tanto en Bilbao

10 La pancarta y el logo de Libropueblo fueron obra de Tomás Adrián Malo, un escenógrafo y diseñador de mucho prestigio, colaborador habitual del director Luis Iturri. Se trataba de una pancarta de grandes dimensiones que les identificaba en sus salidas comerciales y que se sujetaba en dos grandes cañas de pescar del propio Pinilla que tenían guardadas en Bilbao, en el mismo almacén en el que guardaban los libros después de las ventas. Rapha Bilbao (2016) recuerda que el almacén pertenecía al comercio «Curtidos Calle», situado en la calle Somera, 40. Lamentablemente, las legendarias inundaciones de Bilbao de 1983 provocaron que muchos de aquellos ejemplares quedaran inservibles.

11 Este sistema de difusión de las obras protagonizado por el propio autor recuerda el caso pintoresco de los yomiuri, antecesores de los diarios japoneses, en que los autores eran a su vez editores y distribuidores; tras redactar los textos, «el autor los imprimía y, además, los vendía él mismo en las calles, anunciando a gritos los pasajes más importantes» (Escarpit, 1971: 57 y 88).

12 De la clasificación de los escalones del éxito de Escarpit (1971: 106), las ventas de Libropueblo supusieron (con la excepción del último número) un éxito «normal», al corresponderse la venta con las previsiones de los editores. 
como en los pueblos, pero también realizaron viajes comerciales a Madrid ${ }^{13}$ (tanto en El Rastro como en las fiestas anuales del PCE), Pamplona o San Sebastián ${ }^{14}$. En ocasiones, acudieron también a la salida de los trabajadores de las grandes empresas como Altos Hornos o Babcock Wilcox de Sestao ${ }^{15}$, promoviendo de este modo una interacción con el lector que fue fundamental para reavivar las energías que el proyecto requería. A partir de la publicación de los números 4 y 5 (Clementina Bragamonte y Andanzas de Txiki Baskardo), la editorial logró ampliar su red de distribución, incrementando su presencia en las librerías. A través de la venta directa lograron aumentar la red de suscripciones en más de quinientas personas que pagaban contra reembolso los envíos de cada nuevo número (Rapha, 2016). Fue indudable, en este sentido, la eficacia de una técnica publicitaria tan cercana y acotada al posible cliente final $y$, por tanto, tan potencialmente influyente en su decisión de compra ${ }^{16}$.

La propia estructura de la editorial obligaba, sin embargo, a vender prácticamente todos los ejemplares de cada tirada antes de enfrentarse a la edición y publicación de la obra siguiente; de hecho, el fracaso de ventas de la última obra publicada supuso el fin del proyecto. Para paliar la incertidumbre, el autor debía participar del riesgo con su presencia y su energía en el proceso de venta. Su ciclo de vida era, consecuentemente, particular, ya que las obras que tuvieron más éxito no pudieron almacenarse como existencias por mucho tiempo: solo se reeditaron los dos primeros números. Hay que resaltar, sin embargo, que la labor de selección de las obras fue una labor que, necesariamente, no pudo ejecutarse con excesivo rigor, dada la nula voluntad del colectivo de escritores a participar en una empresa semejante y la priorización de la función social y divulgativa del proyecto.

\section{Las Cuentas de Libropueblo}

En su primer número, apareció en la última página del ejemplar el desglose que con pocas variaciones acompañaría a los números de la editorial

13 Anónimo (1979): «La primera venta en Madrid se colocará el domingo en el Rastro. Hasta el día 22 seguirán en plazas y calles, excepto el miércoles 18, que lo harán en la librería Ámbito".

14 En San Sebastián realizaron su presentación en agosto de 1979 (Deia, 9 de agosto de 1979) y entablaron una relación cercana con los redactores de las revistas de literatura Kantil (1975-1976) y, posteriormente, Kurpil (1977-1981).

15 Altos Hornos de Vizcaya tenía aproximadamente once mil trabajadores, más de la mitad de los cuales salían a la vez al finalizar su turno, lo que facilitó que lograran alcanzar un promedio de venta de un centenar de ejemplares en cada ocasión.

16 Como explica Felipe Garduño (2016): «Las elecciones de 1979, primeras elecciones municipales en democracia, unidas a la libertad de prensa recién estrenada, permitieron que los ayuntamientos tuvieran competencias e iniciativas en materia de cultura. Este hecho también favoreció la venta ambulante en la que se basaba Libropueblo». 
hasta el número 7, Poemas para sirena. El cuadro que se muestra a continuación muestra los costes habituales: coste de imprenta, los impuestos de impresión, $25 \%$ para librerías, un importe fijo para costes, portes y viajes y un margen de riesgos (para ejemplares no cobrados o deteriorados).

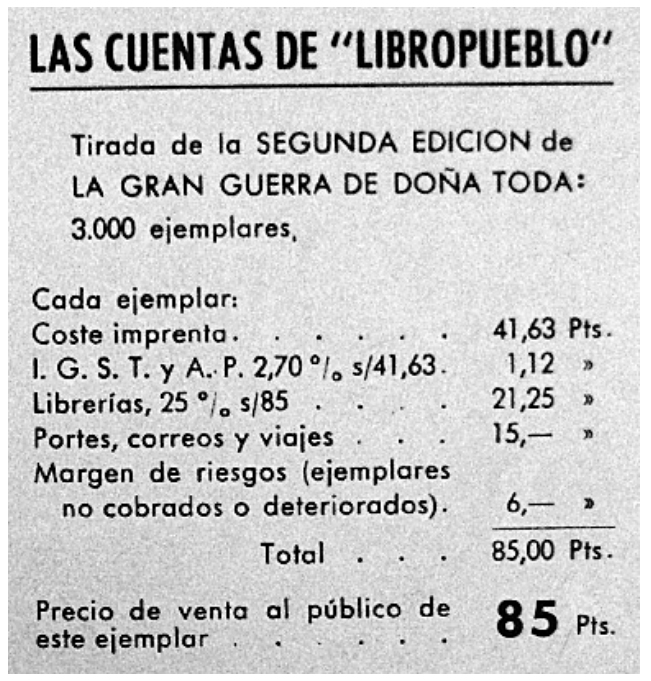

En este número 2, La gran guerra de Doña Toda, ya fue eliminado de las cuentas el $10 \%$ destinado al «Autor» que sí había aparecido en el primero. Asimismo, en su primera edición, se añadieron conceptos como el de «Cuerda y manufactura» (2 pesetas) y 9,55 pesetas de «Margen de riesgos (ejemplares no vendidos o deteriorados, mantenimiento del precio de salida al margen del aumento general de precios, etc.)». Las amplias tiradas (en general, de 3000 ejemplares) tenían, asimismo, una base económica: era una condición que les permitía abaratar al máximo el precio de venta en una organización que renunciaba estructuralmente a los beneficios ${ }^{17}$. Ese precio osciló entre las 50 y 75 pesetas $^{18}$ de los cuatro primeros números (55, 70, 75 y 65 pesetas) hasta llegar a las 250 pesetas del número 5, un ejemplar más extenso y con

17 El estudio de Escarpit (1971: 87-88) relaciona rentabilidad con posibilidad de subsistencia: «en el cuadro de los métodos comerciales tradicionales, el libro barato solo es rentable (y, por lo tanto, posible) si se dirige a un público suficientemente amplio para permitir grandes tiradas».

18 Como precio medio orientativo de los libros en aquellos años, baste saber que, «según una encuesta elaborada por el INLE en 1970, el precio medio de los libros vendidos en 1965 fue de 188 pesetas y este precio evoluciona hasta 1.817 en 1999» (Martínez Alés, 2001: 116). Otras fuentes (El Mundo, 1996) hablan de un precio medio en 1975 de 600 pesetas por «un libro de tapas duras y sobrecubierta». 
ilustraciones en cuatricromía, y las 145 pesetas del número 6. A partir de Poemas para sirena (n. ${ }^{\circ}$ 7, 100 pesetas), Libropueblo reeditó obras publicadas en otras editoriales con un precio de 100 pesetas. Tras el libro de poemas de Gloria Soriano (n. $\left.{ }^{\circ} 11\right)$, las dos últimas obras dejaron de incluir el desglose de costes y salieron a la venta con precios notablemente superiores: Kongobaltza (250 pesetas) y Verdes Valles, colinas rojas, vol. I (500 pesetas), un tomo de 533 páginas que supuso el definitivo fin del proyecto.

\section{El mercado de los bienes Simbólicos}

En Las reglas del arte (1995), Pierre Bourdieu expone que el criterio principal de organización de los campos de producción cultural radica en la relación de las empresas de producción respecto al mercado (y su demanda), una distancia que se equilibra entre dos límites: «la subordinación total y cínica a la demanda y la independencia absoluta respecto al mercado y sus exigencias» (Bourdieu, 1995: 214). Ante estas dos lógicas antagónicas, la posición que adoptó Libropueblo supuso una posibilidad oportuna del sistema: la editorial (y, particularmente, el modo en que esta se definió y posicionó públicamente) se convirtió en sí misma en objeto de mercado y contribuyó a aumentar el capital simbólico de las obras publicadas. Su lógica antieconómica ${ }^{19}$, sin posibilidad de ánimo de lucro para ninguna de las partes que intervenían en el proceso, fue, precisamente, parte de ese capital simbólico que el comprador adquiría con su compra: el modo en que se configuró su posicionamiento desde una voluntad anticapitalista de denuncia supuso uno de los factores fundamentales de diferenciación del producto en el mercado. La compra de un ejemplar de Libropueblo estuvo, de este modo, ligada a la idea de «adquisición ostentatoria» (Escarpit, 1971: 114-115), como signo de reconocimiento y apoyo a un determinado ideario editorial social y político.

Teniendo en cuenta las restricciones innatas a las características de Libropueblo (mercado de ámbito provincial vizcaíno, limitación de los canales de distribución, ausencia de cualquier tipo de difusión o compra concertada con las instituciones públicas, etc.), sí podemos afirmar (en terminología de Bourdieu, 1995: 237) que el proyecto «hizo época» puesto que fue capaz de «hacer existir una nueva posición más allá de las posiciones establecidas, por delante de estas posiciones». Hay que recalcar que, pese a las apariencias, el número de ventas de Libropueblo no fue nada desdeñable ${ }^{20}$ : las tiradas

19 Bourdieu (1995: 244): «La oposición entre el arte y el dinero es una estructura que tiende hoy en día a funcionar como una estructura mental, organizando la producción y la percepción de los productos».

20 Según el Observatorio de la Lectura y el Libro de MECD, en 2015 «la tirada media se situó en 2.810 ejemplares por título». 
fueron, en general, de 3000 ejemplares y algunos de sus ejemplares tuvieron una acogida más que destacada: Proceso, anatematización y quema de una bruja en un ensayo general, 8000 ejemplares en dos ediciones ${ }^{21}$; La gran guerra de Doña Toda, 7200 ejemplares en dos ediciones; Clementina Bragamonte, alcahueta y mártir, tirada única de 7500 ejemplares y Andanzas de Txiki Baskardo, 5000 ejemplares $^{22}$. Esta acogida no puede ser entendida sin tener en cuenta el posicionamiento ideológico de la editorial que respondió, de manera consciente y fruto de las nuevas posibilidades que permitía la libertad, a la nueva situación social que se abrió durante la transición, lo que provocó esa coincidencia de voluntades y motivaciones entre «productores» y «consumidores». Vender y comprar Libropueblo fue, esencialmente, un producto del posfranquismo y permitió la posibilidad de consumir ideología utópica para un receptor reivindicativo ya integrado en una sociedad de consumo: «la acción revolucionaria, reposeída como capital cultural, fue elaborada, traducida, vendida y consumida como artículo de consumo» (Vilarós, 1998: 80).

\section{Cuadro-resumen de las obras publicadas por Libropueblo}

\begin{tabular}{|c|l|l|c|c|c|c|}
\hline$N^{\circ}$ & \multicolumn{1}{|c|}{ Autor } & \multicolumn{1}{|c|}{ Título/Género } & Año & PVP & Págs. & Tirada \\
\hline 1 & $\begin{array}{l}\text { Ramiro Pinilla y y } \\
\text { José Javier Rapha } \\
\text { Bilbao }\end{array}$ & $\begin{array}{l}\text { Proceso, anatematización } \\
\text { y quema de una bruja } \\
\text { en un ensayo general } \\
\text { (Teatro) }\end{array}$ & 1978 & 60 pts. & 43 & $\begin{array}{c}\text { Dos ediciones: } \\
3000 \text { y 5000 } \\
\text { ejemplares }\end{array}$ \\
\hline 2 & Ramiro Pinilla & $\begin{array}{l}\text { La gran guerra de Doña } \\
\text { Toda (Novela) }\end{array}$ & 1978 & 70 pts. & $\begin{array}{l}50 \text { (doble } \\
\text { columna) }\end{array}$ & $\begin{array}{c}\text { Dos ediciones: } \\
4200 \text { y } 3000\end{array}$ \\
\hline 3 & Javier Urquijo & Mi dimensión (Poesía) & 1978 & 75 pts. & 52 & 3000 \\
\hline 5 & $\begin{array}{l}\text { José Javier Rapha } \\
\text { Bilbao }\end{array}$ & $\begin{array}{l}\text { Clementina Bragamonte, } \\
\text { alcahueta y mártir } \\
\text { (Novela) }\end{array}$ & 1979 & 65 pts. & $\begin{array}{l}50 \text { (doble } \\
\text { columna) }\end{array}$ & 7500 \\
\hline 6 & VV.AA. & $\begin{array}{l}\text { Andanzas de Txiki } \\
\text { Baskardo (Relatos) }\end{array}$ & 1980 & 250 pts. & $\begin{array}{l}140 \text { (doble } \\
\text { columna) }\end{array}$ & 5000 \\
\hline 7 & Jucientos contra la & 1981 & 145 pts. & 72 & 3000 \\
\hline
\end{tabular}

21 Obra ganadora del V Festival de Teatro Actual de Sitges (1971), representada por el Grupo Akelarre de Bilbao dirigido por Luis Iturri, quien prologa esta edición.

22 Esta obra se editó en edición bilingüe castellano-euskara, con traducción de Josu Cepeda y con varias ilustraciones a cuatro colores realizadas por alumnos de escuelas cercanas a Getxo. 


\begin{tabular}{|c|l|l|c|c|c|c|}
\hline$N^{\circ}$ & \multicolumn{1}{|c|}{ Autor } & \multicolumn{1}{|c|}{ Título/Género } & Año & \multicolumn{1}{c|}{ PVP } & Págs. & Tirada \\
\hline 8 & Ramiro Pinilla & Seno (Novela) & 1982 & 100 pts. & 307 & Reedición ${ }^{23}$ \\
\hline 9 & $\begin{array}{l}\text { José Javier Rapha } \\
\text { Bilbao }\end{array}$ & $\begin{array}{l}\text { Doña Anita de Gon-Ber } \\
\text { (Novela) }\end{array}$ & 1982 & 100 pts. & 188 & Reedición \\
\hline 10 & Ramiro Pinilla & $\begin{array}{l}\text { iRecuerda, oh, recuerda! } \\
\text { (Relatos) }\end{array}$ & 1982 & 100 pts. & 194 & Reedición \\
\hline 11 & Gloria Soriano & $\begin{array}{l}\text { Etxekoandre, ícómo te } \\
\text { sientes? (Poesía) }\end{array}$ & 1982 & 100 pts. & 53 & 3000 \\
\hline 13 & José Javier Rapha & $\begin{array}{l}\text { Kongobaltza. } \\
\text { Buevosblancos (Novela) }\end{array}$ & 1984 & 250 pts. & 172 & 3000 \\
\hline
\end{tabular}

\section{Conclusiones}

José Carlos Mainer (Mainer y Juliá, 2000: 11) retoma la idea de Frank Kermode (El sentido de un final, 1966) según la cual, en toda transición subyace una conciencia implícita de vivir más allá de un límite y de estar en el umbral de algo muy distinto. De esa sensación resultan, probablemente, los desencantos y sobresaltos que a ellas van ligadas. En este sentido, Libropueblo/Herriliburu supuso un modesto intento de ruptura entre la literatura y la edición comercial capitalista y constituyó un episodio ejemplificador de la historia cultural de la transición española. A través de unos presupuestos ideológicos anticapitalistas, lograron, en un primer momento, que muchos lectores se identificaran tanto con la editorial como con los libros publicados. Sin embargo, sus objetivos estructurales (provocar una respuesta del Estado o de la sociedad al problema de la comercialización del libro) no lograron verse cumplidos. Su intención primera fue tratar de convencer a la mayor parte posible de escritores para que participara en su proyecto y no cabe duda de que esa voluntad frustrada fue uno de los principales motivos de su desaparición: ningún escritor (que ya tuviera editorial) quiso voluntariamente participar en esta iniciativa ya que, desde su punto de vista, los presupuestos de Libropueblo constituían un ataque a la dignidad del oficio y a sus posibilidades socioeconómicas (Rapha Bilbao, 2016). Tanto Pinilla como Rapha eran conscientes de que su proyecto no era la solución y de que una estructura editorial como Libropueblo no podría funcionar en el tiempo; sin embargo, en ambos autores se mantuvo, al igual que otros protagonistas de

${ }^{23}$ Las reediciones se realizaron mediante la recuperación de los ejemplares que quedaban sin vender en las editoriales de origen correspondientes, por lo que ha sido imposible recuperar el número exacto de ejemplares editados por Libropueblo. 
aquellos tiempos excesivos ${ }^{24}$, el orgullo de haber podido llevar a cabo una idea justa, después de cuatro décadas de silencio amordazador. Al respecto, nos comentaba el propio Pinilla (2014):

Fue una locura la idea de Libropueblo, pero eran tiempos distintos. Franco había muerto ayer. Después de cuarenta años, había que hacer algo. Y Libropueblo salió así, una denuncia de los libros. Claro, hoy no tiene sentido vender a precio de coste. Ganar el $5 \%$ en lugar del $30 \%$ tiene algún sentido, pero vender a precio de coste como vendíamos, no.

Desde ese punto de vista editorial, Libropueblo/Herriliburu funcionó con una estructura adecuada a sus fines, lo que permitió su desarrollo a lo largo de varios años; sin embargo, el proyecto trató de soslayar el inevitable «problema del financiamiento» (Escarpit, 1971: 44-48) que atenaza, finalmente, a cada escritor. Sin financiación interna (por los derechos de autor) ni externa (a través del mecenazgo), solo quedaba la posibilidad del autofinanciamiento, extremo que sí permitió la viabilidad de la editorial, pero no así la de los escritores, que tuvieron que recurrir a otra fuente de financiación para mantenerse ${ }^{25}$. Esta segunda vía de financiación denota, de hecho, la autolimitación en los efectos que la propia propuesta comportaba ya que, esta segunda profesión dispensa a la propia sociedad (Escarpit, 1971: 48) «de plantear y resolver el problema de la integración del oficio de las letras a su sistema económico-social».

Desde el punto de vista político, el proyecto estuvo ligado desde el inicio a las actividades del Partido Comunista. Tras sus reiterados fracasos electorales en las elecciones, tanto Ramiro Pinilla como Rapha Bilbao y la mayoría de los colaboradores que participaron en el desarrollo de Libropueblo, sintieron que el vocabulario y las aspiraciones del marxismo habían dejado de formar parte del horizonte ideológico de la sociedad española y fueron abandonando aquellas posiciones de forma relativamente rápida ${ }^{26}$. En este sentido, la desaparición de Libropueblo fue un efecto más del hundimiento

${ }^{24}$ Como, por ejemplo, Jorge Berlanga, que explicaba el surgimiento de la movida madrileña como «una necesidad visceral y espontánea, producto más quizás de un requerimiento inconsciente de la época que de una reflexión intelectual» (Vilarós, 1998: 27).

25 Para reemplazar al inexistente mecenazgo, Taha Hussein (1954: 74) proponía el «segundo oficio» como la solución menos mala, aunque, en el fondo, es posible considerarlo como una forma de autofinanciamiento (Escarpit, 1971: 47).

26 Juan Marsé, en una entrevista concedida a Ajoblanco (Vilarós, 1998: 70), recordaba esa sensación en relación a su novela Últimas tardes con Teresa: «Cuando uno se afiliaba en aquellos años [los sesenta] al PC era porque creía firmemente que el país iba camino de un gran cambio, que luego se ha logrado solo parcialmente. Pero en muchas cosas llevábamos la venda en los ojos, como después se demostró. El amor que Teresa siente por el Pijoaparte se cuece sobre todo sobre este equívoco». 
del proyecto político del Partido Comunista en los años posteriores a la transición ${ }^{27}$. En Euskadi, además, la hegemonía del Partido Nacionalista Vasco a partir del inicio de los años ochenta, tuvo un efecto crucial en el ánimo político y social: el desencanto no solo llegó a las filas del Partido Comunista, sino también al resto de partidos situados a su izquierda, «que creían haber desaprovechado una situación prerrevolucionaria» (Garduño, 2016). Las coordenadas sociopolíticas habían cambiado y ello influyó en la gradual decadencia de apoyos y motivaciones que, hasta ese momento, habían acompañado al proyecto editorial ${ }^{28}$.

Desde un punto de vista literario, el recorrido de Libropueblo ejemplifica la decisiva relación que se establece entre la editorial escogida para publicar una obra (incluso, la colección y el formato elegidos) y la recepción final de la obra. De hecho, Bourdieu (1995: 250) señala un «efecto de armonía preestablecida» según el cual, cada obra de cada autor posee un lugar natural de edición (ya existente o que hay que crear) por lo que, si se rompe esa coordinación, el producto estará abocado al fracaso. Según este efecto, si las obras no se ajustan a su receptor en el mercado, no serán capaces de lograr el éxito comercial y simbólico, lo que explica que las obras con mayor éxito de ventas en Libropueblo fueron las que mejor coincidieron con la forma propia de la editorial ${ }^{29}$. Esta fue una de las razones comerciales que puede ayudar a comprender la decadencia de la editorial: los números 8 (Seno), 9 (Doña Anita de Gon-Ber) y 10 (Recuerda, oh, recuerda) no se escribieron con la intención de ser publicadas en Libropueblo, sino que habían salido ya a la venta en otras editoriales (Planeta, Luis Haranburu y Ediciones del Centro, respectivamente) y se «recuperaron» para la editorial con una nueva portada y un texto explicativo. Esta idea corrobora, asimismo, la causa del final definitivo del proyecto a raíz del fracaso del tomo I de Verdes Valles, colinas rojas, una obra de más de 500 páginas que salió a la venta con un precio mucho más

27 De acuerdo con el estudio de Vilarós (1998: 76), a pesar de la importancia creciente de las asociaciones clandestinas en los años anteriores a la muerte de Franco, no existió en España una militancia política mayoritaria. El verdadero deseo (consciente o inconsciente) de la sociedad era la integración en el aparato económico global impulsado por el capitalismo tardío.

28 No puede resultar azarosa, en este sentido, la coincidencia entre la decadencia de Libropueblo a partir de 1982 y los catastróficos resultados del PCE en las elecciones generales (3,8\% de los votos).

29 Hay que subrayar, en este sentido, que los autores dejaron de escribir novelas adecuadas al formato de Libropueblo a partir del n. 5 de la editorial: Andanzas de Txiki Baskardo; cuando decidieron publicar de nuevo obras inéditas, lo hicieron con novelas que ya no respetaban la idea original de la editorial y que no mantenían la homología estructural entre forma, contenido y público receptor. 
elevado del habitual y que, además, se anunciaba como la primera parte de una trilogía, una propuesta contradictoria con el espíritu inicial de la editorial ${ }^{30}$.

Por último, desde una perspectiva más personal, no se pueden obviar los caminos individuales que ambos autores tomaron en sus carreras: Rapha Bilbao abandonó el oficio de escritor comercial y focalizó su actividad en otros quehaceres profesionales y académicos. En el caso de Pinilla ${ }^{31}$, en 1986, sus tareas literarias se concentraron en la creación de los tomos restantes de su obra magna, Verdes valles, colinas rojas, en la que estuvo trabajando en total veinte años de su vida y que supuso, finalmente, su reconocimiento y consagración como escritor. De ese hecho, resulta una de las paradojas más interesantes: la constatación de que Verdes Valles, colinas rojas, la obra que supuso el reconocimiento literario de Ramiro Pinilla y la que le afianzó en el sistema literario español fue, a su vez, la que puso punto final a su proyecto editorial, tras un rotundo fracaso de crítica y ventas. En este caso, fue necesaria la intervención de una editorial profesional de prestigio (y, evidentemente, sustentadora de las reglas del campo editorial) como Tusquets para que su obra magna alcanzara el reconocimiento que la publicación en Libropueblo le había negado.

\section{Bibliografía}

Anónimo (1978): «PPor fin! Libros buenos, bonitos y baratos». Punto y hora, 2-8 de febrero, pág. 47.

- (1979): «Libropueblo, una iniciativa editorial vasca para abaratar la cultura». El País, 13 de abril.

- (1982): «Los libros del pueblo. La historia de unos escritores que no quieren beneficios». Cambio 16, 568, 18 de octubre.

Aramburu, F. (2006): «Ramiro Pinilla y la perseverancia». El mundo (El cultural), 16 de marzo.

Bourdieu, P. (1995): Las reglas del arte. Génesis y estructura del campo literario. Barcelona, Anagrama.

Carrillo, S. (2006): Memorias. Barcelona, Planeta.

Ceberio, J. (1977): «Gran actividad de socialistas y comunistas en el País Vasco». El País, 26 de abril.

30 Este hecho, unido a todos los demás, indica que las preocupaciones de Pinilla estaban, en ese momento final, más orientadas a la creación de su obra magna que a la continuación de la propia editorial.

31 Además de emprender la creación de la revista Galea, una publicación que se editó durante dieciocho años (1982-2000), que en sus primeros seis meses estuvo ligada a Euskadiko Ezkerra y que se cerró tras un incendio provocado por un atentado de Jarrai. 
Cepeda, J. (2014): «Ramiro Pinilla». Galde, 20 de diciembre (en línea: <http://www. galde.eu/es/ramiro-pinilla> [consulta: 7 de febrero de 2018]).

Díaz de Guereñu, J.M. (2015): «El hambre y la novela, Antonio B. el Ruso». En Acillona, M. (ed.): Ramiro Pinilla. El mundo entero se llama Arrigúnaga. Bilbao, Universidad de Deusto, págs. 109-125.

Erroteta, P. y Elordi, C. (1980): «Ramiro P. El Rojo». La Calle, 131, pág. 48.

Escarpit, R. (1971): Sociología de la literatura. Barcelona, Oikos-tau.

Garduño, F. (2016): Entrevista personal, Sestao.

GonzÁlez, E. (2012): «Ramiro Pinilla y Enric González o los secretos de la vida». Jot Down Magazine, julio (en línea: <http://www.jotdown.es/2012/07/page/4> [consulta: 7 de febrero de 2018]).

Hussein, T. (1954): «L'écrivain dans la société moderne». L'artiste dans la société contemporaine. Paris, unEsco, págs. 72-87.

igartua, P.E. y Díez Ortiz, J. (1978): «Ramiro Pinilla, novelista». Kantil, 7, págs. 33-36.

Landaburu, A. (2010): «La lucha como camino, no destino». El País, 1 de febrero.

Mainer, J.C. (1990): «1975-1985: The Powers of the Past». En Amell, S. (ed.): Literature, the Arts, and Democracy. London-Toronto, Fairleigh Dickinson Aup, págs. 16-37.

Mainer, J.C. y Juliá, S. (2000): El aprendizaje de la libertad (1973-1986). La cultura de la transición. Madrid, Alianza.

Martínez Alés, R. (2001): «El sector editorial español». Información Comercial Española (ICE), 792, págs. 109-123.

Pérez Carrera, J.M. (2014): «Adiós a Ramiro Pinilla, un vasco universalista y comunista». Crónica popular, 3 de noviembre.

Pérez Díaz, V. (1980): Clase obrera, orden social y conciencia de clase. Madrid, Fundación del Instituto Nacional de Industria.

- (1993): La primacía de la sociedad civil. Madrid, Alianza.

Pinilla, R. (2014): Entrevista personal, Walden (Getxo).

Radcliff, P. (2007): «La ciudadanía y la transición a la democracia». En Pérez Ledesma, M. (ed.): De súbditos a ciudadanos. Una historia de la ciudadanía en España. Madrid, Centro de Estudios Políticos y Constitucionales, págs. 343-372.

Rapha Bilbao, J.J. (2016): Entrevista personal, Getxo.

SÁnChez LEón, P. (2010): «Radicalism without Representation: On the Character of Social Movements in the Spanish Transition to Democracy». En Alonso, G. y Muro, D. (eds.): The politics and Memory of Democratic Transition. The Spanish Model. New York-London, Routledge, págs. 95-112.

TARrow, S. (1995): «Mass mobilization and regime change: pacts, reform, and Popular Power in Italy (1918-1922) and Spain (1975-1978)». En Gunther, R. et al. (eds.): The politics of democratic consolidation: Southern Europe in comparative perspective. Baltimore, The Johns Hopkins University Press, págs. 204-230. 
Vilarós, T.M. (1998): El mono del desencanto. Una crítica cultural de la transición española (1973-1993). Madrid, Siglo XXI.

Wilhelmi casanova, G. (2014): Izquierda revolucionaria y movimientos sociales en la transición: Madrid, 1975-1982. Tesis doctoral. Madrid, Universidad Autónoma de Madrid (en línea: <http://hdl.handle.net/10486/661871> [consulta: 7 de febrero de 2018]). 